\title{
MicroRNA function and dysregulation in bone tumors: the evidence to date
}

\author{
This article was published in the following Dove Press journal: \\ Cancer Management and Research \\ 7 January 2014 \\ Number of times this article has been viewed
}

\section{Mary Nugent}

Department of Orthopaedic Surgery, Cappagh National Orthopaedic Hospital, Finglas, Dublin, Ireland
Correspondence: Mary Nugent Department of Orthopaedic Surgery, Cappagh National Orthopaedic Hospital, Cappagh Road, Finglas West, Dublin II, Ireland

Email nugentmary@gmail.com
Abstract: Micro ribonucleic acids (miRNAs) are small non-coding RNA segments that have a role in the regulation of normal cellular development and proliferation including normal osteogenesis. They exert their effects through inhibition of specific target genes at the posttranscriptional level. Many miRNAs have altered expression levels in cancer (either increased or decreased depending on the specific miRNA). Altered miRNA expression profiles have been identified in several malignancies including primary bone tumors such as osteosarcoma and Ewing's sarcoma. It is thought that they may function as tumor suppressor genes or oncogenes and hence when dysregulated contribute to the initiation and progression of malignancy. miRNAs are also thought to have a role in the development of bone metastases in other malignancies. In addition, evidence increasingly suggests that miRNAs may play a part in determining the response to chemotherapy in the treatment of osteosarcoma. These molecules are readily detectable in tissues, both fresh and formalin fixed paraffin embedded and, more recently, in blood. Although there are fewer published studies regarding circulating miRNA profiles, they appear to reflect changes in tissue expression. Thus miRNAs may serve as potential indicators of disease presence but more importantly, may have a role in disease characterization or as potential therapeutic targets. This review gives a brief overview of miRNA biochemistry and explores the evidence to date implicating these small molecules in the pathogenesis of bone tumors.

Keywords: microRNA, primary bone tumor, osteosarcoma, Ewing's sarcoma, metastases, cancer

\section{Introduction}

Micro ribonucleic acids (miRNAs) are small single-stranded non-coding RNAs of 19 to 25 ribonucleotides in length, that are encoded in both plant and animal genomes. ${ }^{1}$ Each miRNA is assigned a species prefix (hsa for humans) and an individual numerical identifier. ${ }^{2,3}$ Since identification of the first microRNA (in Caenorhabditis elegans) by Lee et al in 1993, ${ }^{4}$ over 1,800 individual miRNAs have been identified in humans and this number continues to grow exponentially. ${ }^{5-10}$

The normal functions of miRNAs include regulation of pathways in cell differentiation, cell cycle progression, and apoptosis. ${ }^{11}$ miRNAs downregulate the expression of target genes by either inducing messenger RNA (mRNA) degradation or by translational inhibition at the post transcription level. ${ }^{11-15}$

miRNAs were first linked with cancer in 2002, initially with chronic lymphocytic leukemia (CLL), and subsequently with many other types of malignancies. ${ }^{1}$ Expression of many miRNAs has been found to be altered in malignancy (either overexpressed or reduced, depending on the specific miRNA), with some thought to 
behave as tumor suppressor genes and others as oncogenes. Thus, dysregulation of miRNA expression may contribute to development of cancer through loss of these controls. These cancer-related changes may represent a means of detection or characterization of malignancy through quantification of miRNA expression or, more importantly, may act as future therapeutic targets.

Following a brief outline of miRNA biochemistry, this review focuses on the role of miRNAs in bone tumors, particularly osteosarcoma and Ewing's sarcoma. To date, there is a dearth of research relating to the role of miRNAs in other primary bone tumors, however it is possible that they too are significantly influenced by miRNA-related changes. The role of miRNAs in metastasis of other malignancies to bone is also considered.

A literature search was performed using the PubMed database (US Library of Medicine, Bethesda, MD, USA) with the following medical subject headings (MeSH) terms: microRNA, bone, primary bone tumor, bone metastasis, osteosarcoma, Ewing's sarcoma, and chondrosarcoma. Articles not written in English were excluded. All relevant studies were then reviewed in detail. In view of the relative heterogeneity of the studies identified, their findings are largely described individually in the relevant sections of this paper rather than assimilating all results collectively.

\section{miRNA biochemistry}

miRNAs are the product of miRNA genes that are found as independent transcripts or within the introns of another gene. They are transcribed by RNA polymerase II as primary transcripts (pri-miRNAs). These are then processed into short 70-nucleotide precursor-miRNAs (pre-miRNAs) by an RNA specific ribonuclease enzyme complex (DROSHA). These processes take place within the cell nucleus and the pre-miRNAs are then transported to the cytoplasm by exportin 5. In the cytoplasm, these pre-miRNAs are further cleaved by the endonuclease (Dicer) generating mature miRNAs. ${ }^{16-18}$

In contrast to other genetic material, mature miRNAs do not code specific proteins. However, they regulate protein production in the cell by binding to complementary target mRNAs via the RNA-induced silencing complex (RISC). ${ }^{18-20}$ The RISC pairs perfectly with its target mRNAs to inhibit protein expression by cleavage and degradation of mRNA. ${ }^{16,21}$ miRNAs may also bind to imperfect complementary sites within the $3^{\prime}$ untranslated regions (3'UTR) of mRNA targets resulting in translational inhibition of gene expression. ${ }^{16,17}$ Finally, miRNAs may interfere with protein translation in polyribosomes. The overall effect of any of these actions is a reduction in the production of the protein product by the target gene. ${ }^{18}$

\section{Regulation of miRNA expression}

miRNA expression is tightly regulated via several mechanisms including specific translational regulation, deoxyribonucleic acid (DNA) methylation, and histone deacetylation, DNA copy alteration, and gene mutations affecting proteins involved in processing and maturation. ${ }^{16,22}$ Epigenetic changes such as DNA methylation and histone modification are associated with chromatin remodeling and regulation of gene expression in mammalian development and human diseases, including cancer. ${ }^{23}$ DNA methylation does not always take place alone, but often occurs in the presence of other epigenetic modifications, such as histone modification. ${ }^{23}$ While DNA methylation leads to miRNA silencing, histone modification, especially methylation, can either trigger or suppress miRNA expression, depending on the target amino acid residues and the extent of methylation. ${ }^{23}$ Other proposed influences on miRNA expression include genetic polymorphisms on miRNA 3'UTR binding sites and p53 tumor suppressor gene expression. ${ }^{24}$

\section{Methods of detection and quantification of miRNAs}

miRNAs are readily detectable in cell lines and in tissues, both fresh frozen and formalin fixed paraffin-embedded (FFPE). ${ }^{25}$ Although the majority of published work focuses on tissues and cell lines, recent evidence indicates that they are also resistant to degradation by endogenous circulating ribonucleases and hence stable in circulation, thus readily quantifiable in plasma and blood. ${ }^{26}$

Several methods of detection and quantification of miRNAs have been developed. These include direct detection methods such as Northern blotting and in situ hybridization techniques, hybridization-based microarray platforms, and single miRNA approaches such as quantitative reverse transcriptase-polymerase chain reaction (RT-PCR). ${ }^{27,28}$ Microarray platforms, while expensive, have the advantage of allowing high throughput miRNA profiling and they are particularly useful in identifying miRNAs of interest for further investigation. Although early microarray technology could not distinguish between signals from pre-miRNA, primiRNAs, and mature miRNA sequences, labeling and probe design have improved to address this poor specificity. ${ }^{29,30}$ An alternative high-throughput miRNA profiling technique is a bead-based flow cytometric approach which offers high 
specificity for closely related miRNAs as hybridization occurs in solution. ${ }^{31}$ The most commonly used method of quantifying microRNA expression is RT-PCR; however, its reliability depends on correct normalization to stably expressed controls, usually endogenous. ${ }^{32,33}$ RT-PCR is a relatively low cost and efficient means of miRNA analysis and is particularly useful for validating data obtained from miRNA microarray expression profiling.

\section{Role of miRNAs in oncogenesis}

miRNAs are involved in the control of many cellular processes including development, differentiation, apoptosis, and metabolism. Aberrant miRNA expression patterns have recently been identified in a range of human diseases including many cancers. ${ }^{16}$ This dysregulation of miRNA expression can influence carcinogenesis if the relevant target mRNAs are encoded by tumor suppressor genes or oncogenes. As each miRNA has a potentially large number of targets, even small variations could have significant implications for the cell. ${ }^{17,20}$ Many human miRNA genes are thought to be located in cancer-associated regions or at fragile sites of chromosomes which are prone to deletion, amplification and mutations in cancer cells. ${ }^{16-18}$

As miRNAs function as negative regulators of gene expression, overexpression of oncogenic miRNAs can contribute to tumorigenesis by promoting cellular proliferation and evasion of apoptosis. Reduced expression of tumor suppressive miRNAs may have similar effects. ${ }^{34}$ Both increases and decreases in the expression of specific miRNAs have been demonstrated in cancer; these appear to be tissue-specific and characteristic of cancer type. ${ }^{17,18}$

\section{miRNAs and primary bone tumors}

Primary bone tumors encompass a wide range of tumor types; however, many of these are relatively rare. At the time of writing, most of the published studies relating to miRNAs and primary bone tumors are specific to osteosarcoma or Ewing's sarcoma.

\section{Osteosarcoma}

Osteosarcoma is the most common malignant tumor of bone with an incidence of 4-5 cases per million, mainly in adolescents and young adults. ${ }^{35}$ It arises from mesenchymal stem cells that undergo disruption to normal osteoblast differentiation. ${ }^{36,37}$ Although the 5-year survival rate has improved to approximately $60 \%-70 \%$, a significant proportion of patients still respond poorly to chemotherapy (one of the most important prognostic factors) and have a risk of relapse or metastasis even after curative resection and chemotherapy. ${ }^{35,38,39}$

\section{Osteosarcoma tumorigenesis}

The $m i R-34$ family ( $m i r-34 a$, $m i R-34 b$, and $m i R-34 c$ ) affects expression of target genes, partially in a p53-dependent manner, and expression is decreased in osteosarcoma samples compared to tumor adjacent normal tissues. ${ }^{40}$ The Notch signaling pathway is involved in maintaining the balance between cell proliferation and differentiation and altered Notch signaling has been associated with various disorders, including cancer. ${ }^{41,42} \mathrm{miR}-34 \mathrm{c}$ inhibits osteoblast differentiation and increases osteoclastogenesis through suppression of Notch signaling (resulting in inhibition of osteoprotegerin expression) in mouse models. ${ }^{43}$ This is illustrated in Figure 1. Diallyl trisulphide (DATS), a naturally occurring organosulfur compound derived from Allium vegetables, can inhibit cell cycle progression and induce apoptosis. ${ }^{44}$

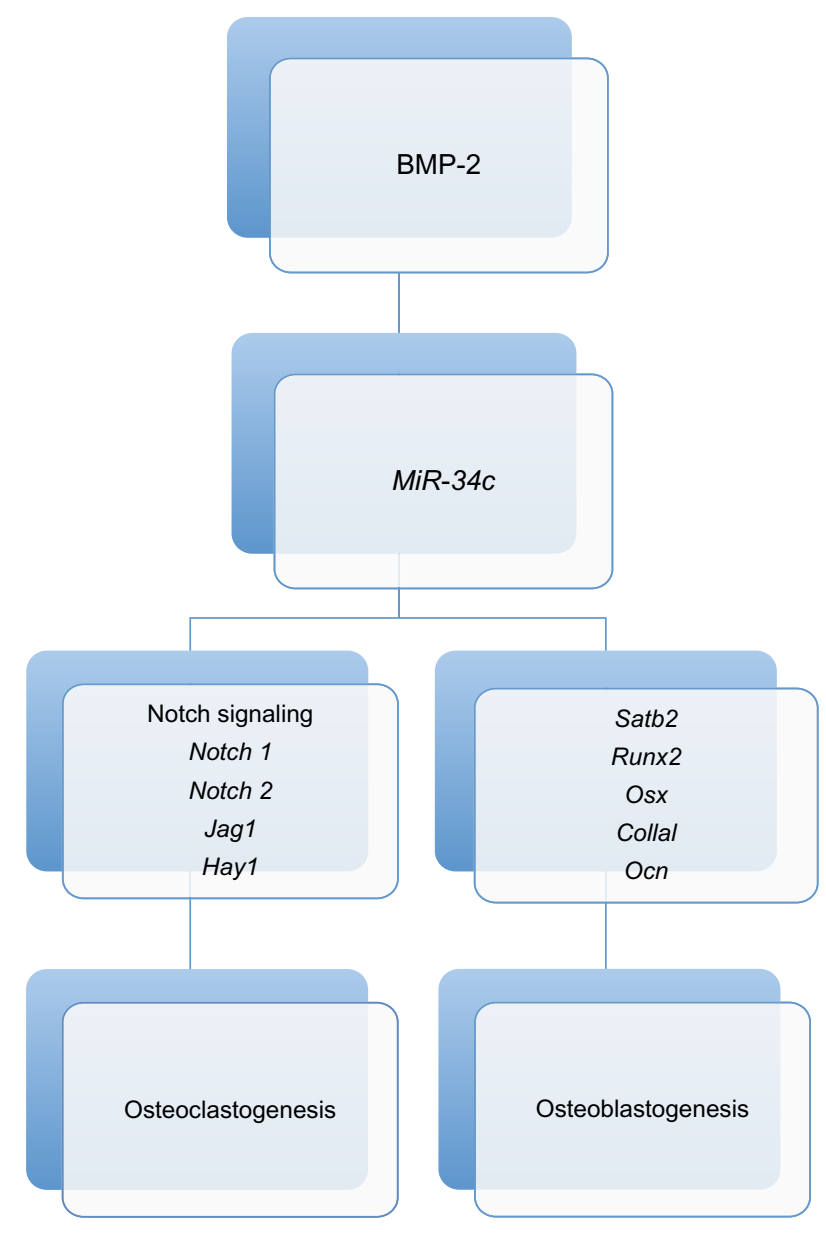

Figure I miR-34c-mediated regulation of bone development. Both osteoclastogenesis and osteoblastogenesis are regulated by miR-34c through targeting of Runx2, Satb2, and multiple factors in the Notch signaling pathway. Abbreviation: BMP, bone morphogenetic protein. 
One study found that DATS suppressed cell survival, invasion and angiogenesis in osteosarcoma cells and these effects were associated with decreased expression of Notch-1 and its downstream genes as well as increased expression of a panel of tumor-suppressive microRNAs including $m i R-34 a$, $m i R-143, m i R-145$, and $m i R-200 b / c$ that are typically lost in osteosarcoma ${ }^{45}$ Re-expression of $m i R-34 a$ and $m i R-200 b$ by transfection led to reduced expression of Notch- $1 .^{45} \mathrm{miR}-34 \mathrm{a}$ has also been shown to be a direct transcriptional target of the p53 tumor suppressor and to inhibit osteosarcoma cell proliferation and metastasis, possibly via downregulation of the $c$ Met gene. ${ }^{46}$

Lysophosphatidic acid acyltransferase $\beta$ (LPAAT $\beta$ ) is thought to regulate osteosarcoma cell proliferation, at least partially via the mammalian target of rapamycin (mTOR) and Raf-1 signaling pathways, however the mechanisms responsible for regulation of LPAAT $\beta$ expression remain unclear. Enhanced LPAAT $\beta$ expression correlates with osteosarcoma cell proliferation and this is inhibited by inducing overexpression of $m i R-24$, which is reduced in osteosarcoma cells. ${ }^{47}$

Insulin like growth factor-1 receptor (IGF1R) is a receptor tyrosine kinase that mediates IGF1-induced signaling events and has pivotal roles in cellular processes such as proliferation, cell migration, and differentiation. ${ }^{48}$ miR-16 overexpression inhibits the Raf1-mitogen-activated protein kinase (MAPK)/extracellular signal-regulated kinase (ERK; collectively MEK1/2)-ERK1/2 pathway and silences IGF1R, inducing cell growth inhibition and a G0/G1 phase arrest; however, $m i R-16$ is downregulated in osteosarcoma cell lines and tissues. ${ }^{49}$

The microRNA cluster (including miR-127-3p, miR-154, miR-299-5p, miR-329, miR-337-3p, miR-376a, miR-376c, miR-377, miR-382, miR-409-3p, miR-409-5p, miR-410, miR432, miR-493, miR-495, miR-453, miR-654-5p, and miR-758) at the chromosome $14 \mathrm{q} 32$ locus is significantly downregulated in osteosarcoma compared to normal bone tissues. ${ }^{50}$ The cMyc oncogene is inhibited by this miRNA cluster, thus miRNA downregulation at this locus results in inhibition of apoptosis through increased cMyc activity. ${ }^{50,51} \mathrm{An}$ inverse correlation has been demonstrated between aggressive tumor behavior (such as increased metastatic potential and accelerated time to death) and the residual expression of representative 14q32 miRNAs (miR-134, miR-382, and $m i R-544$ ) in samples from human osteosarcoma patients. ${ }^{52}$ In addition, a study of 65 human FFPE osteosarcoma tissues (from biopsies) and 26 paired post-chemotherapy resection specimens demonstrated an association between expression of several 14q32-associated miRNAs ( $m i R-139-5 p$, miR-299,
miR-299-3p, miR-323-3p, miR-323-5p, miR-379, miR-382, $m i R-411, m i R-493, m i R-539$, and $m i R-758)$ and recurrencefree survival. ${ }^{52}$

Several miRNAs showing altered expression levels in osteosarcoma tissues or cell lines are shown in Table 1.

\section{Progression and invasion}

The lungs are a common site of metastasis for osteosarcoma and the ability for osteosarcoma cells to migrate and invade is influenced by miRNAs, though these mechanisms have not yet been fully elucidated. The ability of osteosarcoma cells to metastasize to the lungs is inversely correlated with cell surface Fas expression as Fas ligand (L) is constitutively expressed in lungs and can mediate apoptosis in $\mathrm{Fas}^{+}$ cells. $.^{53,54} m i R-20 a$ is encoded by the $m i R-17-92$ cluster and overexpression in cell lines results in downregulation of Fas expression..$^{55}$ One study showed that mir-143 was the most downregulated miRNA in human osteosarcoma cell lines in a mouse model; however, in vitro transfection of miR-143 decreased cell invasiveness and intravenous injection of miR-143 suppressed lung metastasis of 143B sarcoma cells in the mouse model. ${ }^{56}$

Other miRNAs have also been associated with development of metastases; compared to non-metastatic osteosarcomas, metastatic osteosarcomas showed higher expression of $m i R-181 c, m i R-27 a$, and $m i R-93,57,58$ while lower expression of $m i R-183$ in tumor tissues correlates with lung metastases and local recurrence. $.^{59} \mathrm{miR}-183$ is thought to inhibit the metastasis of osteosarcoma through inhibiting motility and invasion by downregulation of the Ezrin gene. ${ }^{60}$

$m i R-335$ expression is lower in osteosarcoma tissues and cell lines than normal controls, and this downregulation is significantly associated with lymph node metastases. ${ }^{61}$ Rho associated, coiled-coil containing protein kinase 1 (ROCK1) has been identified as a target gene and its expression was found to be inversely correlated with $m i R-335$ in osteosarcoma tissues.$^{61}$ Knockdown of ROCK1 inhibits osteosarcoma cell migration and invasion in vitro ${ }^{61}$ and it is also a target of $m i R-340$, which is frequently downregulated in osteosarcoma tumors and cell lines. ${ }^{62}$

\section{miRNAs as prognostic indicators}

As mentioned above, the most important prognostic indicator in osteosarcoma is the response to neoadjuvant chemotherapy. To date, there is no satisfactory means of selecting those who are likely to respond well; however, miRNAs appear to play a role in modulating the response to chemotherapy. A number of studies have looked at the effects of miRNAs on commonly 
Table I miRNAs shown to have altered expression in osteosarcoma tissues or cell lines with their role and target where known

\begin{tabular}{|c|c|c|c|}
\hline \multicolumn{2}{|c|}{ Increased expression } & \multicolumn{2}{|c|}{ Decreased expression } \\
\hline miRNA & Role and target gene (if known) & miRNA & Role and target gene (if known) \\
\hline$\left.\operatorname{miR-2}\right|^{101,108}$ & $\begin{array}{l}\text { Cell invasion and migration via } \\
\text { regulation of RECK }\end{array}$ & $\operatorname{miR}-16^{49}$ & Inhibition of cell proliferation via IGFIR \\
\hline $\operatorname{miR}-93^{58}$ & $\begin{array}{l}\text { Increases cell proliferation } \\
\text { and invasion }\end{array}$ & $\operatorname{miR}-24^{47}$ & $\begin{array}{l}\text { Inhibition of osteosarcoma cell proliferation via LPAAT } \beta \\
\text { downregulation }\end{array}$ \\
\hline$m i R-135 b^{109}$ & & $\operatorname{miR}-29 a^{110}$ & Induces apoptosis \\
\hline $\operatorname{miR}-150^{109}$ & & $\operatorname{miR}-29 b^{110}$ & \\
\hline $\operatorname{miR}-210^{65}$ & & $\operatorname{miR}-3 I^{\prime \prime \prime}$ & $\begin{array}{l}\text { Osteogenic differentiation of mesenchymal stem cells via regulation } \\
\text { of bone transcription factor osterix }\end{array}$ \\
\hline $\operatorname{miR}-22 I^{64}$ & $\begin{array}{l}\text { Induces cell survival via } \\
\text { inhibition of PTEN }\end{array}$ & $\operatorname{miR}-34 a^{45, I 12}$ & Inhibition of cell proliferation via Notch-I inhibition \\
\hline $\operatorname{miR}-199 b-5 p^{113}$ & Involved in Notch signaling & $\operatorname{miR}-34 b$ & \\
\hline $\operatorname{miR}-218$ & & $\operatorname{miR}-34 c^{114}$ & Suppresses proliferation of osteoblasts by downregulation of Runx2 \\
\hline $\operatorname{miR}-542-5 p^{109}$ & & $\operatorname{miR}-125 b^{115}$ & Suppresses proliferation via downregulation of STAT3 \\
\hline \multirow[t]{11}{*}{$\operatorname{miR}-652^{109}$} & & $\operatorname{miR}-132^{68}$ & Facilitates angiogenesis \\
\hline & & $\operatorname{miR}-133 a^{116}$ & Promotes apoptosis by targeting $\mathrm{Bcl}-\mathrm{xL}$ and $\mathrm{Mcl}-\mathrm{I}$ \\
\hline & & $\operatorname{miR}-143^{101}$ & \\
\hline & & $\operatorname{miR}-145^{45,69}$ & Inhibition of cell proliferation via Notch-I inhibition \\
\hline & & $\operatorname{miR}-183^{59}$ & Suppresses Ezrin-linked migration and invasion \\
\hline & & $\operatorname{miR}-199 a-3 p^{101,117}$ & Regulates cell proliferation \\
\hline & & $m i R-200^{45}$ & Inhibition of cell proliferation via Notch-I inhibition \\
\hline & & $m i R-206^{67}$ & Involved in apoptosis and inhibition of cell invasion and migration \\
\hline & & $\operatorname{miR}-335^{61}$ & Suppresses migration and invasion by targeting ROCKI \\
\hline & & $\operatorname{miR}-340^{62}$ & Suppresses proliferation, migration and invasion by targeting ROCKI \\
\hline & & $m i R-424^{118}$ & Inhibits migration and invasion via fatty acid synthase \\
\hline
\end{tabular}

Abbreviations: IGFIR, Insulin like growth factor-I receptor; LPAAT $\beta$, lysophosphatidic acid acyltransferase $\beta$; miRNA, micro ribonucleic acid; PTEN, phosphatase and tensin homolog; RECK, reversion-inducing-cysteine-rich protein with kazal motifs; ROCKI, Rho associated, coiled-coil containing protein kinase I; Runx, runt-related transcription factor; STAT3, signal transducer and activator of transcription 3.

used chemotherapy agents, such as methotrexate, ifosfamide, 5-fluorouracil, and raltitrexed. In one study, a panel of five miRNAs were studied in 27 FFPE tissue samples, cell lines and samples from a rat model. Significant differences in miRNA expression between good responders to ifosfamide and poor responders were observed (miR-92a, miR-99b, $m i R-193 a-5 p$, and $m i R-422 a$ were increased and $m i R-132$ was reduced in good responders) $.^{63} \mathrm{miR}-221$ is significantly increased in osteosarcoma cell lines compared to osteoblasts and has been shown to induce cell survival and cisplatin resistance and reduce apoptosis while $m i R-221$ knockdown reverses these effects. ${ }^{64} \mathrm{miR}-210$ expression is also increased in osteosarcoma tissues compared to noncancerous bone tissues from the same patients and upregulation is associated with larger tumor size, poor response to pre-operative chemotherapy and lower overall survival and progression-free survival. ${ }^{65}$ Overexpression of $m i R-140$ has also been shown to cause chemoresistance to methotrexate and 5-fluorouracil in xenograft models. ${ }^{66}$ In one small study, tissue samples from patients with chemoresistant osteosarcomas underexpressed $m i R-15 b$ and $m i R-451$ compared to samples from those with chemosensitive tumors. ${ }^{57}$
A number of miRNAs have shown altered expression associated with poor disease-free and/or overall survival in osteosarcoma. These include $m i R-206$, which is inversely associated with clinical stage (and thought to be a promoter of apoptosis), ${ }^{67}$ and miR-132, low expression of which is associated with poorer overall and disease-free survival in patients with primary osteosarcoma. ${ }^{68}$ Low miR-145 expression has also been identified as an independent prognostic factor for both overall and disease-free survival in a cohort of 166 patients. Those who had lower osteosarcoma tissue levels of $m i R-145$ had significantly poorer 5-year overall and disease-free survival. ${ }^{69} \mathrm{~A}$ separate study analyzing cancerous and non-cancerous bone tissues in 92 pediatric patients with osteosarcoma showed significant upregulation of $m i R-214$ in osteosarcoma tissues. ${ }^{70}$ This study also found significant correlations between $m i R-214$ expression and prognostic factors such as tumor size, presence of metastases, and poor response to neoadjuvant chemotherapy as well as shorter overall and progression-free survival. ${ }^{70}$ In addition, underexpression of the miRNA cluster at the 14q32 chromosomal locus has been shown to be predictive of chemoresponse, recurrence, and survival, as described in the previous section. ${ }^{52,71}$ 
Table 2 summarizes the miRNAs that have been shown to have some value as prognostic indicators.

\section{Ewing's sarcoma}

Ewing's sarcoma is a member of the Ewing family of tumors (EFT) and, unlike most other primary tumors of bone, has a characteristic translocation most commonly involving chromosomes 11 and $22 .^{72}$ These translocations give rise to fusion genes comprising of the Ewing's sarcoma breakpoint 1 gene and one of several of its family members of transcription factors. ${ }^{73}$ The most common of these fusion genes, EWS-FLI1, is expressed in $85 \%-90 \%$ of $\mathrm{EFT}^{73,74} \mathrm{EWS} / \mathrm{FLI} 1$ forms a transcriptional complex with RNA helicase A (RHA) and this complex has been implicated in the pathogenesis of Ewing's sarcoma. ${ }^{75}$

EWS/FLI1 has been shown to induce changes in miRNA expression profiles in Ewing's sarcoma, most notably $m i R$ 145 and let-7a. miR-145 is markedly reduced in Ewing's sarcoma cell lines and expression dramatically increases on knockdown of EWS-FLI1. ${ }^{76}$ Conversely, ectopic expression of miR-145 in Ewing's sarcoma cell lines strongly reduced EWS-FLI1 protein and transfection of an anti-miR to $m i R-145$ increased EWS-FLI1 levels. ${ }^{76}$ This modulation of EWS-FLI1 protein was mediated by miR-145 targeting the FLI1 3'UTR. ${ }^{76}$ Forced miR-145 expression halted the Ewing's sarcoma cell line growth. ${ }^{76}$ Let-7a is a direct EWSFLI-1 target implicated in EFT cell tumorigenicity through its effect on expression of the target oncogene high-mobility group AT-hook (HMGA2) ${ }^{77}$ Systemic delivery of let-7a into EFT bearing mice restored its expression in tumor cells, decreased HMGA2 expression levels, and resulted in EFT growth inhibition in vivo. ${ }^{77}$

The DNA repair protein and transcriptional cofactor $E Y A 3$ is highly expressed in Ewing's sarcoma cell lines compared to mesenchymal stem cells and it is regulated by the EWS/ FLI1 fusion protein transcription factor via repression of $m i R$ 708, an miRNA that targets the EYA3 $3^{\prime}$ UTR. ${ }^{78}$ High levels of EYA3 correlate significantly with low levels of $m i R-708$ in Ewing's sarcoma tissue samples and are associated with chemoresistance. ${ }^{78}$

Microarray analysis of samples from 49 patients with primary Ewing's sarcoma identified a signature of five miRNAs ( $m i R-34 a, m i R-23 a, m i R-92 a, m i R-490-3 p$, and $m i R-130 b$ ) as an independent predictor of risk for disease progression and survival. ${ }^{79}$ In particular, $m i R-34 a$ expression was associated with both event-free and overall survival. Patients with the highest expression of miR-34a did not experience adverse events in 5 years, while those with the lowest expression levels had recurrence within 2 years. ${ }^{79}$ Further functional analysis of $m i R-34 a$ in EWS cell lines indicated that when $m i R-34 a$ expression was enforced, cells were less proliferative and showed greater sensitivity to doxorubicin and vincristine. ${ }^{79}$

Table 3 summarizes a number of miRNAs shown to have altered expression profiles in Ewing's sarcoma cells compared to mesenchymal stem cells.

\section{Other primary bone tumors}

As stated earlier, published research to date in the area of miRNAs and primary bone tumors focuses mainly on

Table 2 MicroRNAs as prognostic indicators

\begin{tabular}{|c|c|c|}
\hline MicroRNA & Association with prognosis & Mechanism of action (if known) \\
\hline$m i R-34 a$ & Associated with greater event-free and overall survival ${ }^{79}$ & \\
\hline $\operatorname{miR}-92 a$ & Increased in good responders to ifosfamide for osteosarcoma ${ }^{63}$ & \\
\hline $\operatorname{miR}-99 b$ & Increased in good responders to ifosfamide for osteosarcoma ${ }^{63}$ & \\
\hline \multirow[t]{2}{*}{$\operatorname{miR}-132$} & Associated with disease-free and overall survival in osteosarcoma ${ }^{68}$ & \\
\hline & Reduced in good responders to ifosfamide for osteosarcoma ${ }^{63}$ & \\
\hline $\operatorname{miR}-136$ & $\begin{array}{l}\text { Inversely associated with development of lung metastases in giant cell tumor } \\
\text { of bone }^{87}\end{array}$ & $\begin{array}{l}\text { Increased NFIB gene expression } \\
\text { (controls transcription and replication) }\end{array}$ \\
\hline $\operatorname{miR}-140$ & Associated with chemoresistance to methotrexate and 5 -fluorouracil ${ }^{66}$ & \\
\hline $\operatorname{miR}-145$ & Inversely associated with disease-free and overall survival in osteosarcoma ${ }^{69}$ & \\
\hline $\operatorname{miR}-183$ & Inversely associated with lung metastases and local recurrence in osteosarcoma ${ }^{59}$ & $\begin{array}{l}\text { Inhibition of motility and invasion via } \\
\text { downregulation of the Ezrin gene }{ }^{60}\end{array}$ \\
\hline $\operatorname{miR}-193 a-5 p$ & Increased in good responders to ifosfamide for osteosarcoma ${ }^{63}$ & \\
\hline $\operatorname{miR}-206$ & Inversely associated with clinical stage in osteosarcoma ${ }^{67}$ & Promoter of apoptosis \\
\hline $\operatorname{miR}-210$ & $\begin{array}{l}\text { Associated with larger tumor size, poor response to pre-operative chemotherapy } \\
\text { and lower overall survival and progression-free survival in osteosarcoma }{ }^{65}\end{array}$ & \\
\hline $\operatorname{miR}-335$ & Inversely associated with presence of lymph node metastases in osteosarcoma ${ }^{61}$ & $\begin{array}{l}\text { Osteosarcoma cell migration and } \\
\text { invasion via ROCKI target gene }\end{array}$ \\
\hline $\operatorname{miR}-422 a$ & Increased in good responders to ifosfamide for osteosarcoma ${ }^{63}$ & \\
\hline
\end{tabular}

Abbreviations: MicroRNA, micro ribonucleic acid; NFIB, nuclear factor I B-type; ROCKI, Rho associated, coiled-coil containing protein kinase I. 
Table 3 Some of the miRNAs shown to be underexpressed in Ewing's sarcoma - the role of each miRNA has not yet been fully elucidated

\begin{tabular}{ll}
\hline miRNA & Role and target gene (if known) \\
\hline let-7a family & Increased expression of HMGA2 oncogene \\
& promotes cell growth in EFT \\
miR-30a-5 $p^{119}$ & $\begin{array}{l}\text { Binds to CD99 } 3^{\prime} \text { UTR decreasing cell } \\
\text { proliferation and invasion }\end{array}$ \\
miR-34a & Reduces cell proliferation and increases \\
& sensitivity to doxorubicin \\
miR- $145^{76,120}$ & Negative feedback control of EWS-FLI \\
miR-708 & Regulation of DNA repair and transcription \\
& via EYA3 gene \\
\hline
\end{tabular}

Abbreviations: $C D$, cluster of differentiation; DNA, deoxyribonucleic acid; EFT, Ewing family of tumors; HMGA2, high-mobility group AT-hook; miRNA, micro ribonucleic acid; UTR, untranslated region.

osteosarcoma and Ewing's sarcoma. In relation to other types of primary bone tumors, there is a paucity of information regarding the role of miRNAs.

Chondrosarcoma is the second most common primary bone malignancy representing around $20 \%$ of malignant primary tumors of bone and affecting mainly adults. ${ }^{80}$ Currently histological grade remains the best indicator of prognosis. ${ }^{72}$ At the time of writing, there were only three published studies investigating microRNA expression in chondrosarcoma. ${ }^{81-83}$ The first found significant downregulation of several miRNAs (let-7a, miR-100, miR-136, miR-222, $m i R-335$, and $m i R-376 a$ ) in chondrosarcoma tissue samples from 20 patients and chondrosarcoma cell lines compared to expression in normal chondrocytes.$^{81}$ The second of these three studies shows the effects of administering cytostatic antiproliferative proline-rich polypeptide (PRP-1) to a human chondrosarcoma cell line. PRP-1 inhibits mammalian target of rapamycin 1 (mTORC1), a complex that controls protein synthesis. This resulted in significant upregulation in expression of tumor suppressor miRNAs ( $m i R-20 a, m i R-125 b$, and $m i R-192)$ and downregulation of cancer-associated miRs (oncomiRs) (miR-490-3p, miR-509-3p, miR-550, and miR589). ${ }^{82}$ Finally, the third study demonstrated upregulation of $m i R-518 b$ with associated downregulation of the antiapoptotic protein Bcl-2 and upregulation of the pro-apoptotic protein Bax in SW1353 human chondrosarcoma cell lines. ${ }^{83}$ Taken together, these studies indicate a role for miRNAs in chondrosarcoma; however, further research needs to take place in this area.

Multiple osteochondromatosis (MO) is an autosomal dominant disease characterized by the growth of multiple osteochondromas. Although benign, they have the potential to undergo malignant transformation into peripheral chondrosarcomas, estimated to occur in $1 \%-5 \%$ of patients. ${ }^{84}$ A recent study investigated miRNA expression in cartilage samples from 19 unrelated MO patients and four controls (undergoing surgery for reasons unrelated to MO) showing a range of differentially expressed miRNAs on microarray, with a signature of eight miRNAs (miR-21, miR-140, miR145, miR-214, miR-195, miR-199a, miR-451, and miR-483) whose combined expression could distinguish between MO samples and control growth plate samples ${ }^{85}$ While this is a small study and the only one thus far to investigate miRNA expression in MO, this may be an area with future potential for diagnostic or therapeutic measures.

Giant cell tumor of bone (GCTB) is a benign but locally aggressive lesion that occasionally metastasizes to the lungs. ${ }^{86}$ Only one published study to date has investigated miRNA expression profiling in these tumors. ${ }^{87}$ Although this was a small study involving tissues from ten GCTB patients, half of whom developed lung metastases, the authors demonstrated a reduced level of $m i R-136$ in patients with metastases compared those with non-metastatic tumors. Furthermore, $m i R-136$ expression was shown to be inversely related to expression of nuclear factor 1 B-type (NFIB; a predicted target gene of $m i R-136$ ) in the primary tumors that developed metastases.

\section{miRNAs and metastatic bone tumors}

The most common malignant tumors involving bone are metastases from carcinomas. These carcinomas are most frequently prostate, breast, and lung cancer; however, renal cell carcinoma, thyroid carcinoma, and melanoma are also common ${ }^{88}$ Involvement of miRNAs in metastasis was first reported in breast cancer by Ma et al in 2007, who showed that $m i R-10 b$ initiates breast cancer invasion and metastasis. ${ }^{89}$ An miRNA hypermethylation profile characteristic of human metastasis was subsequently identified, which suggested that DNA methylation-associated silencing of tumor suppressor miRNAs contributes to the development of human cancer metastasis..$^{90}$ In this study, which used colorectal cancer (SW620), melanoma (IGR37), and head and neck cancer (SIHN-011B) cell lines derived from lymph node metastases, reintroduction of $m i R-148 a, m i R-34 b$, and $m i R-34 c$ into cancer cells with epigenetic inactivation inhibited motility, tumor growth, and metastasis formation in xenograft models, with associated downregulation of miRNA oncogenic target genes such as cMyc, the E2F2 transcription factor, cyclin-dependent kinase 6 (CDK6), and TGIF2. ${ }^{90}$ Additionally, miR-224 overexpression may facilitate metastasis of 
human breast cancer cells to bone via inhibition of the Raf kinase inhibitor protein (RKIP), which normally functions as a tumor suppressor. ${ }^{91}$

A Chinese study using human small cell lung cancer cells in mouse xenograft models found that levels of $m i R-335$ and mir-29a were reduced in SBC-5 cells (which metastasize to bone) compared to SBC-3 cells (which do not), as were receptor activator of nuclear factor kappa-B ligand (RANKL) and IGF-1R (key mediators in bone metastases). ${ }^{92}$ This study also demonstrated that over-expression of $m i R-335$ in SBC-5 cells significantly reduced cell migration, invasion, proliferation, colony formation, and osteoclast induction in vitro. ${ }^{92}$ Overexpression of $m i R-335$ reduced RANKL and IGF-1R expression..$^{92}$ Loss of $m i R-335$ was associated with metastatic osteolytic skeletal lesions. $.^{92} \mathrm{miR}-33 a$ expression is also altered in lung cancer and underexpression may be associated with bone metastasis via increased activity of parathyroid hormone related protein (PTHrP) induced osteoclastogenesis. ${ }^{93}$

The epithelial-mesenchymal transition (EMT) is a key step in the progression of tumor cell metastasis. Human enhancer of filamentin 1 (HEF1) is a positive regulator of EMT, driving migration, invasion, and metastases. $m i R-145$ reduces expression of HEF1 and directly targets it by binding to its $3^{\prime}$ UTR. ${ }^{94}$ HEF1 levels show a negative correlation with miR-145 in prostate cancer and were higher in those with bone metastases, higher PSA levels, or higher Gleason grades. ${ }^{94} \mathrm{miR}-143$ has also been associated with bone metastasis of prostate cancer and may be involved in the regulation of EMT. ${ }^{95}$ miR-203 acts as an anti-metastatic miRNA in prostate cancer through regulation of pro-metastatic genes, including zinc finger E-box binding homeobox (ZEB) 2, B cell-specific Moloney murine leukemia virus integration site, survivin, and bone-specific effectors, such as Runx2. Expression is attenuated in metastatic prostate cancer and reintroduction or overexpression in cell lines has been shown to suppress metastases. ${ }^{96,97}$

\section{Future directions}

The area of miRNA research is still a new field, though expanding exponentially as the immense potential of these small molecules becomes evident. Most of the published studies to date relating to miRNA expression and primary bone tumors have quantified miRNAs in tumor tissue or cell lines; however, recent studies relating to other malignancies have demonstrated that miRNAs can be detected in circulation and these circulating levels may reflect altered tissue expression in disease states. ${ }^{26,98-100}$ At the time of writing, there was only one published study investigating the relationship between circulating miRNAs and primary bone tumors. In this study, plasma levels of $m i R-21$ were significantly higher while plasma $m i R-199 a-3 p$ and $m i R-143$ were decreased in samples from 40 osteosarcoma patients compared to 40 healthy controls. ${ }^{101}$ Circulating $m i R-21$ and $m i R-143$ expression correlated with both metastasis status and histological subtype; however, $m i R-199 a-3 p$ levels only correlated with histological subtype. ${ }^{101}$ This is an area that warrants further investigation as it may hold potential for future application as a means of obtaining relatively noninvasive biomarkers of tumor activity.

Other possible future clinical applications include the use of miRNA pathways as therapeutic targets or miRNA expression profiling as a means of patient selection in order to improve chemotherapy response rates. These could include measures to reduce expression of oncogenic miRNAs, such as miRNA silencing, antisense blocking, and miRNA modifications. Conversely, for miRNAs with tumor suppressor roles, inducing overexpression may inhibit tumor growth. ${ }^{102}$ Although research into miRNAs as therapeutic targets in osteo-oncology is in its infancy, $\mathrm{miR}-302 \mathrm{~b}$ expression has been induced by epirubicin exposure in cell lines and has demonstrated inhibition of osteosarcoma cell proliferation by promoting apoptosis and cell cycle arrest. ${ }^{103}$ In addition, there have been significant advances in development of miRNA therapeutics for management of other diseases. For example, a recent preclinical study showed an inhibitor of miR-122 (SPC3649) to be effective in reduction of hepatitis $C$ viral load in chimpanzees. ${ }^{104}$ In relation to cancer, a number of studies have shown promising results. A single recombinant adenovirus expressing p53 and p21targeting artificial miRNAs was shown to induce apoptosis in human cancer cells. ${ }^{105}$ Wiggins et al have demonstrated anti-oncogenic effects of a synthetic $m i R-34 a$ in a mouse model of non-small-cell lung cancer without elevation of cytokines or liver and kidney enzymes in serum, suggesting that the formula is well tolerated and does not induce an immune response. ${ }^{106}$ Systemic administration of $m i R-10 b$ antagomirs to tumor-bearing mice was shown to markedly suppress breast cancer metastasis (though they did not reduce primary mammary tumor growth) and appears to be well tolerated by normal animals. ${ }^{107}$ While these therapies are not yet directly applicable to bone tumor treatments, they represent significant advances.

The full extent of human miRNA pathways and targets has yet to be determined; however, this group of molecules possesses enormous potential, especially in the field of oncology. Nonetheless, validation and careful evaluation regarding 
possible unwanted side effects of novel miRNA-based therapies are essential prior to introduction into clinical practice.

\section{Disclosure}

The author reports no conflicts of interest in this work.

\section{References}

1. Mirnezami AH, Pickard K, Zhang L, Primrose JN, Packham G MicroRNAs: key players in carcinogenesis and novel therapeutic targets. Eur J Surg Oncol. 2009;35(4):339-347.

2. Ambros V, Bartel B, Bartel DP, et al. A uniform system for microRNA annotation. RNA. 2003;9(3):277-279.

3. Griffiths-Jones S, Saini HK, van Dongen S, Enright AJ. miRBase: tools for microRNA genomics. Nucleic Acids Res. 2008;36(Database issue) D154-D158.

4. Lee RC, Feinbaum RL, Ambros V. The C elegans heterochronic gene lin-4 encodes small RNAs with antisense complementarity to lin-14. Cell. 1993;75(5):843-854.

5. miRBase 20 [homepage on the Internet]. Manchester: The University of Manchester; 2013. Available from: http://www.mirbase.org/index shtml. Accessed September 12, 2013.

6. Griffiths-Jones S. The microRNA Registry. Nucleic Acids Res. 2004;32(Database issue):D109-D111.

7. Griffiths-Jones S. miRBase: the microRNA sequence database. Methods Mol Biol. 2006;342:129-138.

8. Griffiths-Jones S. miRBase: microRNA sequences and annotation. Curr Protoc Bioinformatics. 2010; Chapter 12:Unit 12.9.1-Uni 12.910 .

9. Griffiths-Jones S, Grocock RJ, van Dongen S, Bateman A, Enright AJ. miRBase: microRNA sequences, targets and gene nomenclature Nucleic Acids Res. 2006;34(Database issue):D140-D144.

10. Kozomara A, Griffiths-Jones S. miRBase: integrating microRNA annotation and deep-sequencing data. Nucleic Acids Res. 2011; 39(Database issue):D152-D157.

11. He L, Hannon GJ. MicroRNAs: small RNAs with a big role in gene regulation. Nat Rev Genet. 2004;5(7):522-531.

12. Valencia-Sanchez MA, Liu J, Hannon GJ, Parker R. Control of translation and mRNA degradation by miRNAs and siRNAs. Genes Dev. 2006;20(5):515-524

13. Bartel DP. MicroRNAs: genomics, biogenesis, mechanism, and function Cell. 2004;116(2):281-297.

14. Winter J, Jung S, Keller S, Gregory RI, Diederichs S. Many roads to maturity: microRNA biogenesis pathways and their regulation. Nat Cell Biol. 2009;11(3):228-234.

15. Hammond SM, Caudy AA, Hannon GJ. Post-transcriptional gene silencing by double-stranded RNA. Nat Rev Genet. 2001;2(2):110-119.

16. Li S, Fu H, Wang Y, et al. MicroRNA-101 regulates expression of the v-fos FBJ murine osteosarcoma viral oncogene homolog (FOS) oncogene in human hepatocellular carcinoma. Hepatology. 2009;49(4): 1194-1202.

17. Slaby O, Svoboda M, Michalek J, Vyzula R. MicroRNAs in colorectal cancer: translation of molecular biology into clinical application. Mol Cancer. 2009;8:102

18. Wijnhoven BP, Michael MZ, Watson DI. MicroRNAs and cancer. Br J Surg. 2007;94(1):23-30

19. Faber C, Kirchner T, Hlubek F. The impact of microRNAs on colorectal cancer. Virchows Arch. 2009;454(4):359-367.

20. Rossi S, Kopetz S, Davuluri R, Hamilton SR, Calin GA. MicroRNAs, ultraconserved genes and colorectal cancers. Int J Biochem Cell Biol. 2010;42(8):1291-1297.

21. Cummins JM, Velculescu VE. Implications of micro-RNA profiling for cancer diagnosis. Oncogene. 2006;25(46):6220-6227.

22. Bandres E, Agirre X, Bitarte N, et al. Epigenetic regulation of microRNA expression in colorectal cancer. Int J Cancer. 2009;125(11): 2737-2743.
23. Liu X, Chen X, Yu X, et al. Regulation of microRNAs by epigenetics and their interplay involved in cancer. J Exp Clin Cancer Res. 2013;32(1):96.

24. Xi Y, Shalgi R, Fodstad O, Pilpel Y, Ju J. Differentially regulated microRNAs and actively translated messenger RNA transcripts by tumor suppressor p53 in colon cancer. Clin Cancer Res. 2006;12(7 Pt 1): 2014-2024.

25. Meng W, McElroy JP, Volinia S, et al. Comparison of microRNA deep sequencing of matched formalin-fixed paraffin-embedded and fresh frozen cancer tissues. PLoS One. 2013;8(5):e64393.

26. Mitchell PS, Parkin RK, Kroh EM, et al. Circulating microRNAs as stable blood-based markers for cancer detection. Proc Natl Acad Sci U S A. 2008;105(30):10513-10518.

27. Wark AW, Lee HJ, Corn RM. Multiplexed detection methods for profiling microRNA expression in biological samples. Angew Chem Int Ed Engl. 2008;47(4):644-652.

28. Kloosterman WP, Wienholds E, de Bruijn E, Kauppinen S, Plasterk RH. In situ detection of miRNAs in animal embryos using LNA-modified oligonucleotide probes. Nat Methods. 2006;3(1):27-29.

29. Castoldi M, Schmidt S, Benes V, Hentze MW, Muckenthaler MU. miChip: an array-based method for microRNA expression profiling using locked nucleic acid capture probes. Nat Protoc. 2008;3(2):321-329.

30. Castoldi M, Schmidt S, Benes V, et al. A sensitive array for microRNA expression profiling (miChip) based on locked nucleic acids (LNA). RNA. 2006;12(5):913-920.

31. Lu J, Getz G, Miska EA, et al. MicroRNA expression profiles classify human cancers. Nature. 2005;435(7043):834-838.

32. Kheirelseid EA, Chang KH, Newell J, Kerin MJ, Miller N. Identification of endogenous control genes for normalisation of real-time quantitative PCR data in colorectal cancer. BMC Mol Biol. 2010;11:12.

33. Chang KH, Mestdagh P, Vandesompele J, Kerin MJ, Miller N. MicroRNA expression profiling to identify and validate reference genes for relative quantification in colorectal cancer. BMC Cancer. 2010;10:173.

34. Mirnezami AH, Pickard K, Zhang L, Primrose JN, Packham G. MicroRNAs: key players in carcinogenesis and novel therapeutic targets. Eur J Surg Oncol. 2009;35(4):339-347.

35. Kobayashi E, Hornicek FJ, Duan Z. MicroRNA Involvement in Osteosarcoma. Sarcoma. 2012;2012:359739.

36. Ottaviani G, Jaffe N. The epidemiology of osteosarcoma. Cancer Treat Res. 2009;152:3-13.

37. Tang N, Song WX, Luo J, Haydon RC, He TC. Osteosarcoma development and stem cell differentiation. Clin Orthop Relat Res. 2008;466(9):2114-2130.

38. Bielack SS, Kempf-Bielack B, Delling G, et al. Prognostic factors in high-grade osteosarcoma of the extremities or trunk: an analysis of 1,702 patients treated on neoadjuvant cooperative osteosarcoma study group protocols. J Clin Oncol. 2002;20(3):776-790.

39. Geller DS, Gorlick R. Osteosarcoma: a review of diagnosis, management, and treatment strategies. Clin Adv Hematol Oncol. 2010;8(10): $705-718$.

40. He C, Xiong J, Xu X, et al. Functional elucidation of MiR-34 in osteosarcoma cells and primary tumor samples. Biochem Biophys Res Commun. 2009;388(1):35-40.

41. Wang Z, Li Y, Banerjee S, Sarkar FH. Emerging role of Notch in stem cells and cancer. Cancer Lett. 2009;279(1):8-12.

42. Wang Z, Li Y, Kong D, Ahmad A, Banerjee S, Sarkar FH. Cross-talk between miRNA and Notch signaling pathways in tumor development and progression. Cancer Lett. 2010;292(2):141-148.

43. Bae Y, Yang T, Zeng HC, et al. miRNA-34c regulates Notch signaling during bone development. Hum Mol Genet. 2012;21(13):2991-3000.

44. Li J, Liu W, Zhao K, et al. Diallyl trisulfide reverses drug resistance and lowers the ratio of CD133+ cells in conjunction with methotrexate in a human osteosarcoma drug-resistant cell subline. Mol Med Rep. 2009;2(2):245-252.

45. Li Y, Zhang J, Zhang L, Si M, Yin H, Li J. Diallyl trisulfide inhibits proliferation, invasion and angiogenesis of osteosarcoma cells by switching on suppressor microRNAs and inactivating of Notch-1 signaling. Carcinogenesis. 2013;34(7):1601-1610. 
46. He L, He X, Lim LP, et al. A microRNA component of the p53 tumour suppressor network. Nature. 2007;447(7148):1130-1134.

47. Song L, Yang J, Duan P, et al. MicroRNA-24 inhibits osteosarcoma cell proliferation both in vitro and in vivo by targeting LPAAT $\beta$. Arch Biochem Biophys. 2013;535(2):128-135.

48. Annunziata M, Granata R, Ghigo E. The IGF system. Acta Diabetol. 2011;48(1):1-9.

49. Chen L, Wang Q, Wang GD, et al. miR-16 inhibits cell proliferation by targeting IGF1R and the Raf1-MEK1/2-ERK1/2 pathway in osteosarcoma. FEBS Lett. 2013;587(9):1366-1372.

50. Maire G, Martin JW, Yoshimoto M, Chilton-MacNeill S, Zielenska M, Squire JA. Analysis of miRNA-gene expression-genomic profiles reveals complex mechanisms of microRNA deregulation in osteosarcoma. Cancer Genet. 2011;204(3):138-146.

51. Thayanithy V, Sarver AL, Kartha RV, et al. Perturbation of $14 \mathrm{q} 32$ miRNAs-cMYC gene network in osteosarcoma. Bone. 2012;50(1): 171-181.

52. Sarver AL, Thayanithy V, Scott MC, et al. MicroRNAs at the human $14 \mathrm{q} 32$ locus have prognostic significance in osteosarcoma. Orphanet J Rare Dis. 2013;8:7.

53. Lafleur EA, Koshkina NV, Stewart J, et al. Increased Fas expression reduces the metastatic potential of human osteosarcoma cells. Clin Cancer Res. 2004;10(23):8114-8119.

54. Worth LL, Lafleur EA, Jia SF, Kleinerman ES. Fas expression inversely correlates with metastatic potential in osteosarcoma cells. Oncol Rep. 2002;9(4):823-827.

55. Huang G, Nishimoto K, Zhou Z, Hughes D, Kleinerman ES. miR-20a encoded by the miR-17-92 cluster increases the metastatic potential of osteosarcoma cells by regulating Fas expression. Cancer Res. 2012; 72(4):908-916.

56. Osaki M, Takeshita F, Sugimoto Y, et al. MicroRNA-143 regulates human osteosarcoma metastasis by regulating matrix metalloprotease-13 expression. Mol Ther. 2011;19(6):1123-1130.

57. Jones KB, Salah Z, Del Mare S, et al. miRNA signatures associate with pathogenesis and progression of osteosarcoma. Cancer Res. 2012;72(7):1865-1877.

58. Montanini L, Lasagna L, Barili V, et al. MicroRNA cloning and sequencing in osteosarcoma cell lines: differential role of miR-93. Cell Oncol (Dordr). 2012;35(1):29-41.

59. Zhu J, Feng Y, Ke Z, et al. Down-regulation of miR-183 promotes migration and invasion of osteosarcoma by targeting Ezrin. Am J Pathol. 2012;180(6):2440-2451.

60. Zhao H, Guo M, Zhao G, et al. miR-183 inhibits the metastasis of osteosarcoma via downregulation of the expression of Ezrin in F5M2 cells. Int J Mol Med. 2012;30(5):1013-1020.

61. Wang Y, Zhao W, Fu Q. miR-335 suppresses migration and invasion by targeting ROCK1 in osteosarcoma cells. Mol Cell Biochem. 2013; 384(1-2):105-111.

62. Zhou X, Wei M, Wang W. MicroRNA-340 suppresses osteosarcoma tumor growth and metastasis by directly targeting ROCK1. Biochem Biophys Res Commun. 2013;437(4):653-658.

63. Gougelet A, Pissaloux D, Besse A, et al. Micro-RNA profiles in osteosarcoma as a predictive tool for ifosfamide response. Int $J$ Cancer. 2011; 129(3):680-690.

64. Zhao G, Cai C, Yang T, et al. MicroRNA-221 induces cell survival and cisplatin resistance through PI3K/Akt pathway in human osteosarcoma. PLoS One. 2013;8(1):e53906.

65. Cai H, Lin L, Cai H, Tang M, Wang Z. Prognostic evaluation of microRNA-210 expression in pediatric osteosarcoma. Med Oncol. 2013;30(2):499.

66. Song B, Wang Y, Xi Y, et al. Mechanism of chemoresistance mediated by miR-140 in human osteosarcoma and colon cancer cells. Oncogene. 2009;28(46):4065-4074.

67. Bao YP, Yi Y, Peng LL, et al. Roles of microRNA-206 in osteosarcoma pathogenesis and progression. Asian Pac J Cancer Prev. 2013;14(6):3751-3755.
68. Yang J, Gao T, Tang J, Cai H, Lin L, Fu S. Loss of microRNA-132 predicts poor prognosis in patients with primary osteosarcoma. Mol Cell Biochem. 2013;381(1-2):9-15.

69. Tang M, Lin L, Cai H, Tang J, Zhou Z. MicroRNA-145 downregulation associates with advanced tumor progression and poor prognosis in patients suffering osteosarcoma. Onco Targets Ther. 2013;6: 833-838.

70. Wang Z, Cai H, Lin L, Tang M, Cai H. Upregulated expression of microRNA-214 is linked to tumor progression and adverse prognosis in pediatric osteosarcoma. Pediatr Blood Cancer. 2013.

71. Kelly AD, Haibe-Kains B, Janeway KA, et al. MicroRNA paraffin-based studies in osteosarcoma reveal reproducible independent prognostic profiles at 14q32. Genome Med. 2013;5(1):2.

72. Schwab JH, Springfield DS, Raskin KA, Mankin HJ, Hornicek FJ. What's new in primary bone tumors. J Bone Joint Surg Am. 2012; 94(20):1913-1919.

73. Riggi N, Stamenkovic I. The Biology of Ewing sarcoma. Cancer Lett. 2007;254(1):1-10.

74. Kovar H. Downstream EWS/FLI1 - upstream Ewing's sarcoma. Genome Med. 2010;2(1):8.

75. Kinsey M, Smith R, Iyer AK, McCabe ER, Lessnick SL. EWS/FLI and its downstream target NR0B1 interact directly to modulate transcription and oncogenesis in Ewing's sarcoma. Cancer Res. 2009;69(23): 9047-9055.

76. Ban J, Jug G, Mestdagh P, et al. Hsa-mir-145 is the top EWS-FLI1repressed microRNA involved in a positive feedback loop in Ewing's sarcoma. Oncogene. 2011;30(18):2173-2180.

77. De Vito C, Riggi N, Suvà ML, et al. Let-7a is a direct EWS-FLI-1 target implicated in Ewing's sarcoma development. PLoS One. 2011;6(8): e23592.

78. Robin TP, Smith A, McKinsey E, Reaves L, Jedlicka P, Ford HL. EWS/ FLI1 regulates EYA3 in Ewing sarcoma via modulation of miRNA-708, resulting in increased cell survival and chemoresistance. Mol Cancer Res. 2012;10(8):1098-1108.

79. Nakatani F, Ferracin M, Manara MC, et al. miR-34a predicts survival of Ewing's sarcoma patients and directly influences cell chemo-sensitivity and malignancy. $J$ Pathol. 2012;226(5):796-805.

80. David E, Blanchard F, Heymann MF, et al. The Bone Niche of Chondrosarcoma: A Sanctuary for Drug Resistance, Tumour Growth and also a Source of New Therapeutic Targets. Sarcoma. 2011;2011: 932451.

81. Yoshitaka T, Kawai A, Miyaki S, et al. Analysis of microRNAs expressions in chondrosarcoma. J Orthop Res. 2013;31(12):1992-1998.

82. Galoian KA, Guettouche T, Issac B, Qureshi A, Temple HT. Regulation of onco and tumor suppressor MiRNAs by mTORC1 inhibitor PRP-1 in human chondrosarcoma. Tumour Biol. 2013.

83. Liang W, Li X, Li Y, et al. Gallic acid induces apoptosis and inhibits cell migration by upregulating miR-518b in SW1353 human chondrosarcoma cells. Int J Oncol. 2014;44(1):91-98.

84. Schmale GA, Conrad EU, Raskind WH. The natural history of hereditary multiple exostoses. J Bone Joint Surg Am. 1994;76(7):986-992.

85. Zuntini M, Salvatore M, Pedrini E, et al. MicroRNA profiling of multiple osteochondromas: identification of disease-specific and normal cartilage signatures. Clin Genet. 2010;78(6):507-516.

86. Raskin KA, Schwab JH, Mankin HJ, Springfield DS, Hornicek FJ. Giant cell tumor of bone. J Am Acad Orthop Surg. 2013;21(2):118-126.

87. Mosakhani N, Pazzaglia L, Benassi MS, et al. MicroRNA expression profiles in metastatic and non-metastatic giant cell tumor of bone. Histol Histopathol. 2013;28(5):671-678.

88. Ibrahim T, Mercatali L, Amadori D. Bone and cancer: the osteoncology. Clin Cases Miner Bone Metab. 2013;10(2):121-123.

89. Ma L, Teruya-Feldstein J, Weinberg RA. Tumour invasion and metastasis initiated by microRNA-10b in breast cancer. Nature. 2007; 449(7163):682-688.

90. Lujambio A, Calin GA, Villanueva A, et al. A microRNA DNA methylation signature for human cancer metastasis. Proc Natl Acad Sci USA. 2008;105(36):13556-13561. 
91. Huang L, Dai T, Lin X, et al. MicroRNA-224 targets RKIP to control cell invasion and expression of metastasis genes in human breast cancer cells. Biochem Biophys Res Commun. 2012;425(2):127-133.

92. Gong M, Ma J, Guillemette R, et al. miR-335 Inhibits Small Cell Lung Cancer Bone Metastases via IGF-1R and RANKL Pathways. Mol Cancer Res. Epub 2013 Dec 10.

93. Kuo PL, Liao SH, Hung JY, Huang MS, Hsu YL. MicroRNA-33a functions as a bone metastasis suppressor in lung cancer by targeting parathyroid hormone related protein. Biochim Biophys Acta. 2013;1830(6):3756-3766.

94. Guo W, Ren D, Chen X, et al. HEF1 promotes epithelial mesenchymal transition and bone invasion in prostate cancer under the regulation of microRNA-145. J Cell Biochem. 2013;114(7):1606-1615.

95. Peng X, Guo W, Liu T, et al. Identification of miRs-143 and -145 that is associated with bone metastasis of prostate cancer and involved in the regulation of EMT. PLoS One. 2011;6(5):e20341.

96. Saini S, Majid S, Yamamura S, et al. Regulatory Role of mir-203 in Prostate Cancer Progression and Metastasis. Clin Cancer Res. 2011;17(16):5287-5298.

97. Viticchiè G, Lena AM, Latina A, et al. MiR-203 controls proliferation, migration and invasive potential of prostate cancer cell lines. Cell Cycle. 2011;10(7):1121-1131.

98. Heneghan HM, Miller N, Lowery AJ, Sweeney KJ, Newell J, Kerin MJ. Circulating microRNAs as novel minimally invasive biomarkers for breast cancer. Ann Surg. 2010;251(3):499-505.

99. Nugent M, Miller N, Kerin MJ. Circulating miR-34a levels are reduced in colorectal cancer. J Surg Oncol. 2012;106(8):947-952.

100. Chen X, Ba Y, Ma L, et al. Characterization of microRNAs in serum: a novel class of biomarkers for diagnosis of cancer and other diseases. Cell Res. 2008;18(10):997-1006.

101. Ouyang L, Liu P, Yang S, Ye S, Xu W, Liu X. A three-plasma miRNA signature serves as novel biomarkers for osteosarcoma. Med Oncol. 2013;30(1):340.

102. Osada H, Takahashi T. MicroRNAs in biological processes and carcinogenesis. Carcinogenesis. 2007;28(1):2-12.

103. Zhang Y, Hu H, Song L, Cai L, Wei R, Jin W. Epirubicin-mediated expression of miR-302b is involved in osteosarcoma apoptosis and cell cycle regulation. Toxicol Lett. 2013;222(1):1-9.

104. Lanford RE, Hildebrandt-Eriksen ES, Petri A, et al. Therapeutic silencing of microRNA-122 in primates with chronic hepatitis $\mathrm{C}$ virus infection. Science. 2010;327(5962):198-201.

105. Idogawa M, Sasaki Y, Suzuki H, et al. A single recombinant adenovirus expressing p53 and p21-targeting artificial microRNAs efficiently induces apoptosis in human cancer cells. Clin Cancer Res. 2009; 15(11):3725-3732.

106. Wiggins JF, Ruffino L, Kelnar K, et al. Development of a lung cancer therapeutic based on the tumor suppressor microRNA-34. Cancer Res. 2010;70(14):5923-5930.
107. Ma L, Reinhardt F, Pan E, et al. Therapeutic silencing of miR-10b inhibits metastasis in a mouse mammary tumor model. Nat Biotechnol. 2010;28(4):341-347.

108. Ziyan W, Shuhua Y, Xiufang W, Xiaoyun L. MicroRNA-21 is involved in osteosarcoma cell invasion and migration. Med Oncol. 2011;28(4):1469-1474.

109. Lulla RR, Costa FF, Bischof JM, et al. Identification of Differentially Expressed MicroRNAs in Osteosarcoma. Sarcoma. 2011;2011: 732690 .

110. Zhang W, Qian JX, Yi HL, et al. The microRNA-29 plays a central role in osteosarcoma pathogenesis and progression. Mol Biol (Mosk). 2012;46(4):622-627.

111. Baglìo SR, Devescovi V, Granchi D, Baldini N. MicroRNA expression profiling of human bone marrow mesenchymal stem cells during osteogenic differentiation reveals Osterix regulation by miR-31. Gene. 2013;527(1):321-331.

112. Yan K, Gao J, Yang T, et al. MicroRNA-34a inhibits the proliferation and metastasis of osteosarcoma cells both in vitro and in vivo. PLoS One. 2012;7(3):e33778.

113. Won KY, Kim YW, Kim HS, Lee SK, Jung WW, Park YK. MicroRNA$199 \mathrm{~b}-5 \mathrm{p}$ is involved in the Notch signaling pathway in osteosarcoma. Hum Pathol. 2013;44(8):1648-1655.

114. van der Deen M, Taipaleenmäki H, Zhang Y, et al. MicroRNA-34c inversely couples the biological functions of the runt-related transcription factor RUNX2 and the tumor suppressor p53 in osteosarcoma. J Biol Chem. 2013;288(29):21307-21319.

115. Liu LH, Li H, Li JP, et al. miR-125b suppresses the proliferation and migration of osteosarcoma cells through down-regulation of STAT3. Biochem Biophys Res Commun. 2011;416(1-2):31-38.

116. Ji F, Zhang H, Wang Y, et al. MicroRNA-133a, downregulated in osteosarcoma, suppresses proliferation and promotes apoptosis by targeting Bcl-xL and Mcl-1. Bone. 2013;56(1):220-226.

117. Duan Z, Choy E, Harmon D, et al. MicroRNA-199a-3p is downregulated in human osteosarcoma and regulates cell proliferation and migration. Mol Cancer Ther. 2011;10(8):1337-1345.

118. Long XH, Mao JH, Peng AF, Zhou Y, Huang SH, Liu ZL. Tumor suppressive microRNA-424 inhibits osteosarcoma cell migration and invasion via targeting fatty acid synthase. Exp Ther Med. 2013;5(4):1048-1052.

119. Franzetti GA, Laud-Duval K, Bellanger D, Stern MH, Sastre-Garau X, Delattre O. MiR-30a-5p connects EWS-FLI1 and CD99, two major therapeutic targets in Ewing tumor. Oncogene. 2013;32(33): 3915-3921.

120. Riggi N, Suvà ML, De Vito C, et al. EWS-FLI-1 modulates miRNA145 and SOX2 expression to initiate mesenchymal stem cell reprogramming toward Ewing sarcoma cancer stem cells. Genes Dev. 2010;24(9):916-932.
Cancer Management and Research

\section{Publish your work in this journal}

Cancer Management and Research is an international, peer-reviewed open access journal focusing on cancer research and the optimal use of preventative and integrated treatment interventions to achieve improved outcomes, enhanced survival and quality of life for the cancer patient The journal welcomes original research, clinical \& epidemiological

\section{Dovepress}

studies, reviews \& evaluations, guidelines, expert opinion \& commentary, case reports \& extended reports. The manuscript management system is completely online and includes a very quick and fair peerreview system, which is all easy to use. Visit http://www.dovepress.com/ testimonials.php to read real quotes from published authors. 